\title{
Automated process control system of regional substations retrofit
}

\author{
A $R$ Mirgaleeva* and $K H$ Gilfanov
}

Department of automation of technological processes and productions, Kazan State Power Engineering University, 51 Krasnoselskaya Srteet, Kazan 420066, Russia, Tatarstan

\begin{abstract}
The article presents data on the state of the Digital Substation technology in Russia. Also voiced the advantages and disadvantages of this technology. Since the main disadvantage is the economic inexpediency of introducing digital substations, the article proposed a method to improve the reliability of electricity supply to regional areas.
\end{abstract}

\section{Introduction}

A digital substation (hereinafter referred to as DSS) is a combination of typical equipment and the latest achievements of digital technology. The DSS is an innovative energy development technology of the country. Today, solutions for design, protection, software are offered by leading developers of automated systems, emergency automation, relay protection, measuring equipment, etc [1].

The subject of the implementation of the DSS in the Russian Federation is one of the topics discussed at energy forums, conferences, seminars and exhibitions. In a short time, new developments of microprocessor devices appear, the energy community quickly responds to new trends, which indicates the qualitative development of innovative technologies in the country as a whole. But at the same time, the innovative technology of the "DSS" did not pass on to the ingress of industrial implementation, which was caused by a number of existing problems.

One of the obvious problems of operating companies are the risks that arise when introducing new technical solutions [2].

In addition, there are strategic issues that are often neglected by manufacturers and energy companies, but without solving which the introduction of innovative equipment on an industrial scale is impossible, namely:

- the need to create an industry-wide regulatory and technical base for the development, design and operation of equipment DSS;

- the need to develop specialized tools and training design organizations to design a digital substation [3];

- addressing the issues of metrological certification of automation systems, including automated measuring and information system for electric power fiscal accounting, with the support of IEC 61850-9-2;

- identification of strategic paths for the development of protection and automation systems, including the determination of the optimal structure of the digital substation as a whole and the structure of building individual systems;

- statistics accumulation and digital substation equipment reliability analysis.

In my opinion, the issue of designing digital substations has received less attention than implementation. This is due to the fact that each system can be implemented into an object and run on the basis of working documentation only. But when creating an innovative project for a substation, it is impossible to get along with traditional design methods, it is necessary to create a new computer-aided design system, and in parallel to train design services with it.

There are a number of companies working on the development of tools for automatic design engineering and configuration of a new type of substation (DSS) SCADA Studio. They are based on the standards IEC 61850-6 SCL, IEC 61970 CIM, IEC 61131, and the advantage is minimal manual intervention and the ability to perform testing at different design stages.

The use of open international standards increases interoperability between the software of various equipment suppliers and the design automation system.

On the remaining unresolved issues in the energy sector, more attention should be paid to scientific forums, seminars and to study the practical results of new technologies. Energy companies should finance $\mathrm{R} \& \mathrm{D}$ related to the synthesis of operating experience, assessing the reliability of various options for building DSS, and monitoring the current international level of technology development.

When introducing new technologies, there are always discussions about their advantages and disadvantages. In order to minimize possible risks, the principles and ways of further development of the Digital Substation technology in Russia should be transparent and available for wide discussion by the energy community [4].

\footnotetext{
* Corresponding author: mirgaleeva94@mail.ru
} 
The complex hierarchy of modern electrical networks includes a huge number of various electrical equipment, among which transformer substations play the role of a link connecting and redistributing electricity. They are located near or inside settlements and provide comfortable conditions for people to live.

In rural areas, it is still possible to come across structures of old pole-mounted substations operating in the open air, which receive 10 or $6 \mathrm{kV}$ on the high side of the overhead line and deliver 0.4 to connected consumers.

Inside settlements with high-rise buildings, for safety considerations, cable lines hidden in the ground are more often used, and transformer equipment is located inside special buildings closed to locks against unauthorized entry [5].

And since the introduction of DSS is a rather expensive process, the problem of supplying electricity to rural and regional areas requires finding solutions in the substation structure itself.

An important element of electrical networks and systems, which largely determine the reliability and efficiency of their operation, are power transformers. Malfunctions of transformer equipment, leading to failures in operation or emergency shutdowns, can bring significant losses to power systems and consumers.

Transformer monitoring, which provides continuous monitoring of key parameters during operation, is considered one of the most effective ways to increase the reliability of their operation and to prevent potential accidents in advance in world practice.

One of the most important elements of an energy system that needs to be controlled is a power transformer. Due to the wide variety of defects that occur in a transformer, various methods of their condition monitoring are required [6]. Therefore, at the moment there are a variety of methods of protection and methods of control of power equipment.

\section{Subsystem of control and management of transformer oil regeneration}

Regeneration of transformer oil is an important part of the preventative maintenance mechanism, hence the transformer oil must be cleaned before it reaches a level of deterioration, which can lead to damage to the transformer insulation. If the transformer maintenance program is respected, moisture will not accumulate in the hard part of the insulation and dirt will not accumulate [7].

Frequent criteria for regeneration upon connection:

- The transformer must not contain puff water,

- The dielectric strength must be at least $18 \mathrm{~kW}$.

- Moisture content in oil is more than $40 \mathrm{ppm}$,

- The transformer must not be overloaded until the transformer oil is in poor condition.

If these criteria are not met at the initial stage, the regeneration process should take place without connecting
The process of oil regeneration and cleaning of dirt occurs on-site (possibly in the transformer tank). The oil is pumped out from the bottom of the tank, heated, filtered, degassed and dehydrated before it returns to the top of the transformer through the expansion tank. The process continues until the oil meets the standard or other specifications. The method of oil recovery uses the method of heating, adsorption and vacuuming (water release and degassing). All leaks detected must be repaired before processing the oil.

The difference between regeneration and purification is that purification cannot remove substances such as acids, aldehydes, ketones, etc., dissolved in oil. Thus, the cleaning cannot change the color of the oil from amber to yellow. While regeneration also includes cleaning, filtering, and dehydration.

The on-site regeneration and purification of transformer oil gives the following results [8]:

- Moisture content in oil has dropped less than 10 ppm;

- Acidity dropped to less than $0.02 \mathrm{mgm} \mathrm{KOH} / \mathrm{g}$ oil;

- Breakdown voltage increased by more than 70 $\mathrm{kW}$;

- Interfacial voltage increased to 40 days;

- tgd oil has become equal to or less than 0.003 ;

- Dirt dissolved or became as a suspension in oil, as well as sediment dirt, and removed during the regeneration process;

- The stability of oil oxidation has been restored;

- The color of the oil was restored and turned light yellow;

- Breakdown voltage of solid insulation improved.

\section{Subsystem of control, management and regulation of the transformer cooling system}

Oil cooling with blast and natural oil circulation is used for more powerful transformers. In this case, fans are placed in the mounted coolers of the radiator tubes. The fan draws air from below and blows through the heated upper part of the tubes. The fan starts and stops automatically depending on the load and the oil heating temperature. Transformers with such cooling can operate with a completely disconnected blast, if the load does not exceed $100 \%$ of nominal, and the temperature of the upper oil layers is not more than $55^{\circ} \mathrm{C}$, and also independently of the load at negative ambient temperatures and the oil temperature is not higher than $45^{\circ} \mathrm{C}$. The maximum allowable oil temperature in the upper layers during the operation of a transformer with a nominal load of $95^{\circ} \mathrm{C}$ [9].

The forced cooling of the radiator tubes improves the conditions for cooling the oil and, consequently, the windings and the magnetic core of the transformer, which makes it possible to manufacture such transformers with a capacity of up to $80,000 \mathrm{~kW}$ [10]. 

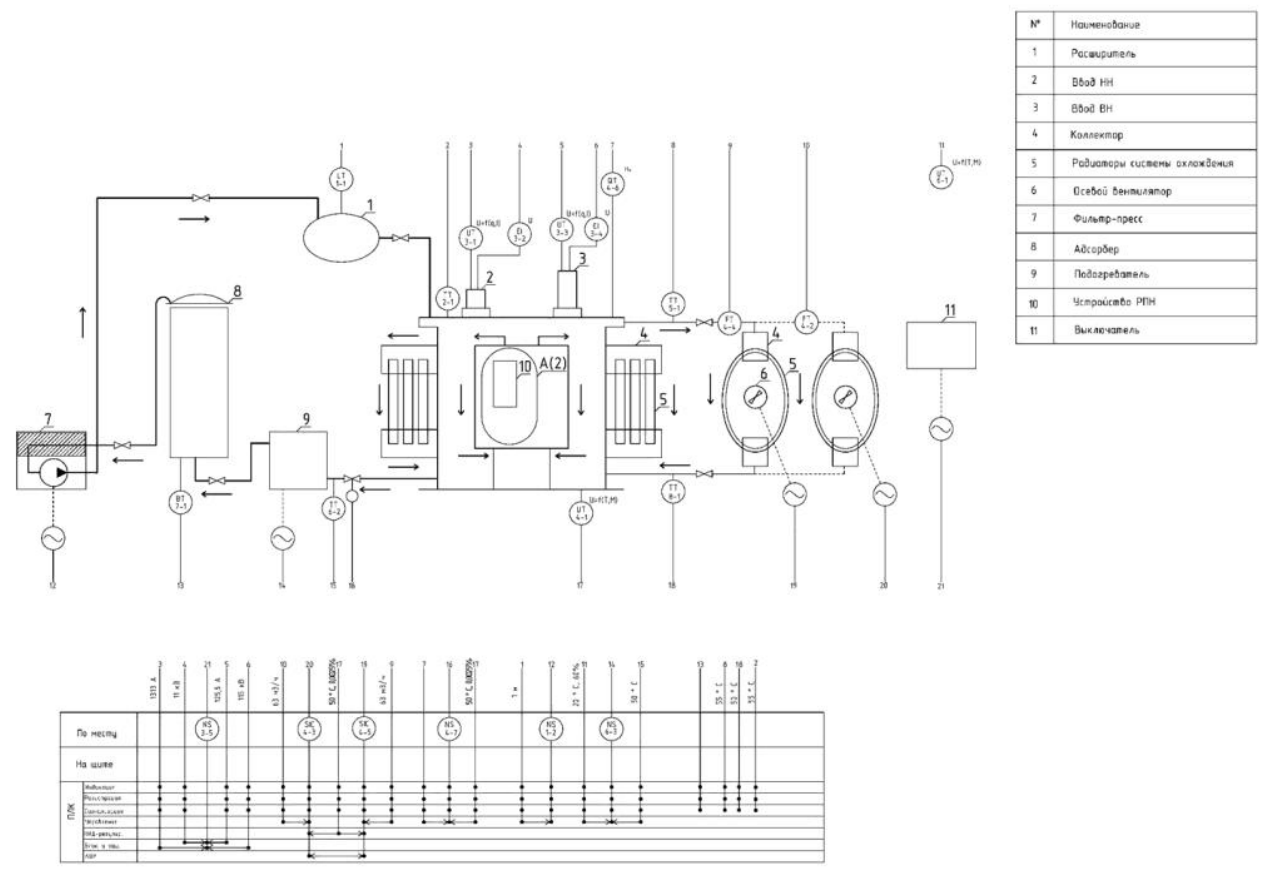

Fig. 2. Functional diagram of the monitoring and control system for a power transformer

\section{Functional diagrams of the monitoring and control system of the power transformer TDTN-25000/110 and the on-load tap changing device in its structure}

\subsection{Subsystem for control of the on-load tap- changer}

Based on the obtained values of nominal voltages at the transformer inputs, the value of the transformation ratio is calculated. If the voltage fluctuations in the network are outside the permissible limits, then the controller generates a signal for switching the on-load tap-changer. After switching, the position number of the tap-changer is fixed and the switching time is read [11].

For continuous monitoring of the status of the onload tap-changer, a PD (partial discharges) recording sensor is installed in the on-load tap-changer tank, and the on-load tap-changer vibration sensor.

The sensor of current consumption by the on-load tap-changer drive and the on-load tap-changer voltage sensor serve to monitor the status of the tap-changer drive, if necessary, the lock and protection are activated.

If the oil temperature sensor in the on-load tapchanger tank detects an excess of the permissible value, the controller generates a signal to turn off the drive of the on-load tap-changer [12].

\subsection{Oil recovery subsystem}

If the moisture content sensor in transformer oil has recorded an excess of the value and (or) a gas analyzer registers an excess of the concentration of gases dissolved in the oil.

The solenoid valve opens and the pump turns on, and the oil begins to flow to the regeneration.

In the event that the inlet temperature of the oil is not sufficient for regeneration, the heating of the oil is activated [13].

Next, the oil enters the adsorber filled with silica gel. From the adsorber, the oil enters the filter press and returns to the expansion tank of the transformer.

A color sensor is installed to record the status of the silica gel.

\subsection{Subsystem of control, management and regulation of the transformer cooling system}

The power transformer TDTN-25000/110 has an oil cooling system with blast and natural circulation of oil.

The oil heated in the transformer tank enters the radiators of the cooling system.

Temperature control occurs with a frequency converter.

A temperature sensor installed inside the tank at the inlet of the cooler captures the value of the regulated temperature and a signal is generated for the frequency converter of the fan drive to maintain the required temperature [14]. 


\section{Conclusion}

The advantage of digital substations compared to traditional CAD systems is the ability to customize and configure automation systems and devices from any manufacturer with a minimum amount of manual work. In addition, the obvious advantage of introducing the DSP is not only the development of domestic science and production, but also an increase in the energy security of the country [15].

However, due to the need for large economic investments, as well as the lack of a unified methodology for the design and implementation of digital substations cannot yet be implemented in practice. That is why the method of improving the reliability of operation of transformers in the composition of regional substations is a constructive solution to the problem of supplying electricity to remote areas.

\section{References}

1. Modern power engineering // Energokonsul. URL: http://www.energocon.com/pages/id1176.html (reference date: 6.03.2019).

2. Electrical system. URL: https://beeindia.gov.in/sites/default/files/3Ch1.pdf (reference date: 20.05.2019).

3. The use of heat power oil transformers for heat supply. URL: https:/www.geoteplo.com.ua/company/85portfolio/77-tn-na-podstancii.html(reference date: 6.03.2019).

4. Energy efficient substation // URL: http://www.ntcpower.ru/field_of_activity/energoeffektivnost/cente r_for_energy_efficiency.php (reference date: 6.03.2019).

5. S.V. Gridin, A.F. Petrenko, The efficiency of the methods of disposal of waste heat from the cooling systems of power transformers, Power Saving. Energy. Energy Audit, 7, 11-18 (2013)

6. Zi-Jie Chien, Hung-Pin Cho, Ching-Song Jwo, SihLi Chen, Yi-Lun Lin, A Study of Waste-Heat Recovery Unit for Power Transformer, Advanced Materials Research Vols, 875-877, 1661-1665 (2014) Online: 2014-02-27 (C) (2014) Trans Tech Publications, doi:10.4028/www.scientific.net/AMR.875877.1661.

7. M. Salari, P. Bayrasy, K. Wolf, Thermal analysis of a three phase transformer with coupled simulation // URL:https://www.researchgate.net/publication/276 057920 17.09.2018 (reference date: 6.03.2019).

8. V.E. Vorotnitsky, Heat recovery systems of transformers and autotransformers 220-750 KB / / energy of a single network, Ed. Science and technology. The centre of FGC UES (Moscow), 6, 32-42 (2014)

9. Using ANSYS Workbench technology to generate finite element grids // URL: https://sapr.ru/article/6779 (reference date: 30.05.2019).
10. ANSYS Maxwell. URL: https://www.ansys.com/products/electronics/ansysmaxwell (reference date: 30.05.2019).

11. A. Nagdewate, T. Paunikar, Computation of single phase distribution transformer faults by finite element method, Journal of Electrical and Electronics Engineering, 2278-1676, 2320-3331, 13-19 URL: http://www.iosrjournals.org/iosrjeee/Papers/NCEERA/volume-2/EE023-

14.pdf?id=7590 (reference date: 30.05 .2019 ).

12. Modeling of heat transfer processes by means of ANSYS // URL finite element analysis package: http://lib.knigi-x.ru/23raznoe/1269361.php17.09.2018 (reference date 6.03.2009).

13. N. Schmidt, S. Tenbohlen, S. Chen, C. Breuer. Numerical and experimental investigation of temperature distribution inside oil-cooled transformer windings https://www.ieh.unistuttgart.de/dokumente/publikationen/2013_Schmid t_Numerical_and_Experimental_Investigation_of t he_Temperature...pdf (reference date: 30.05 .2019$)$.

14. G.V. Kuznetsov, E.V. Kravchenko, A new approach to numerical analysis of reliability indices in electronics, EPJ Web Conf., 82 (2015), doi: 10.1051/epjconf/20158201029

http://earchive.tpu.ru/bitstream/11683/15371/1/mat ecconf_tsotr_20152301021.pdf (reference date: 30.05.2019).

15. R. Vilaithong, S. Tenbohlen, T. Stirl, Improved Topoil Temperature Model for Unsteady-State Conditions of Power Transformers, Proceedings of the XIVth International Symposium on High Voltage Engineering, Tsinghua University, Beijing, China, August 25-29 (2005) https://pdfs.semanticscholar.org/b72d/c718a3f7997 56ab6401363e7b39806e7272e.pdf (reference date: 30.05.2019). 